\title{
Governança Global e a sociedade internacional:mais problemas comuns do que interesses nacionais.
}

\section{Global governance and international society: more common problems than national interests.}

José Alberto Antunes de Mirandal, Sérgio Urquhart de Cademartori ${ }^{2}$

\section{RESUMO:}

A globalização e a crise da soberania intensificaram as críticas sobre a natureza do direito internacional, assim como sobre as leis dos Estados soberanos, do ponto de vista sociológico, funcional e ético. Essas críticas tem frequentemente procurado projetar um valor material ou uma ideia de justiça social externa ao Estado que deveria ser perseguida pelo direito internacional.As sociedades sofrem uma crise de seus modelos democráticos principalmente discussões relativas a representatividade de participação e de legitimidade dos atores políticos envolvidos. As discussões sobre governança, ainda que traga uma carga grande de discursos ideológicos, abre as discussões sobre o espaço publico nos âmbitos local e mundial. Constituise ai novas formas de subordinações e solidariedades cidadãs ante a necessidade de integralas na difícil equação da democracia no âmbito mundial. O objetivo deste artigo é analisar a capacidade da sociedade internacional, das instituições internacionais e do direito internacional de enxergar os problemas comuns da humanidade para além dos interesses nacionais, em tempos de fragmentação, nacionalismos e populismos. A metodologia utilizada é a fenomenológica, constatando os fatos para, a partir dos mesmos, tecer possibilidades explicativas com potencial de fornecer um quadro compreensivo da realidade que se tenta abranger.Conclui-se que a sociedade internacional possui uma infinidade de problemas comuns e que as instituições internacionais, o direito internacional ainda que não consigam sozinhosser efetivos a exercer pressão frente a esses interessespossuem um papel chave no âmbito global.

Palavras-Chave: Governança Global, Sociedade Internacional, problemas comuns, interesses nacionais

\footnotetext{
1 Doutor em Estudos Estratégicos Internacionais pela UFRGS (2012). Atualmente é Assessor de Assuntos Interinstitucionais e Internacionais e professor permanente do Mestrado em Direito e Sociedade além de integrar o corpo docente do Curso de Relações Internacionais da Universidade La Salle.

2 Doutor em Direito pela Universidade Federal de Santa Catarina (1997) e pós-doutorado junto à Unisinos (RS). Atualmente é professor visitante do doutorado da Universidade de Granada e da Universidade Técnica de Lisboa, professor permanente do Centro Universitário La Salle - Canoas, Consultor ad hoc da CAPES.
} 


\begin{abstract}
:
Globalization and the crisis of sovereignty have intensified criticism of the nature of international law as well as the laws of sovereign states from a sociological, functional and ethical point of view. Such criticisms have often sought to project a material value or idea of social justice external to the state that should be pursued by international law.Societies suffer from a crisis of their democratic models, mainly discussions about the representativeness of participation and legitimacy of the political actors involved. The discussions on governance, although it carries a great load of ideological discourses, opens the discussions on the public space in the local and world scopes. New forms of citizen subordination and solidarity are constituted in view of the need to integrate them into the difficult equation of democracy at the global level.The aim of this article is to analyze the capacity of international society, international institutions and international law to see the common problems of humanity beyond national interests in times of fragmentation, nationalism and populism.The methodology used is the phenomenological one, stating the facts for, from the same, to weave explanatory possibilities with the potential to provide a comprehensive picture of the reality that is tried to cover.It is concluded that international society has a myriad of common problems and that international institutions, international law, even if they can not be effective in exerting pressure on these interests alone, play a key role at the global level.
\end{abstract}

Key words: Global Govenance, International Society, common problems, national interests

\title{
1- Introdução
}

Parte-se aqui de uma primeira constatação: a de que o processo de globalização alterou profundamente as forças políticas, socioeconômicas e culturais em todo o mundo. Atualmente observamos esforços populistas que pregam a fragmentação e os extremismos, volta ao nacionalismo salientando que tudo o que foi constituído a partir dela, como as instituições internacionais e o próprio direito internacional são ineficazes. É preciso que se saliente que o processo de globalização é improvável que diminua ou retroceda. O mundo é, para melhor ou pior, interdependente. Esta interdependência écada vez mais profunda e está acontecendo em um momento de deslocamento dos principais atores, tanto em termos de Estados em expansão como em declínio e a importância crescente de vários outros atores não estatais. As instituições internacionais, ainda que isoladamente tenham dificuldade de atuar, são a resposta necessária aos anseios de uma sociedade internacional que cada vez mais terá de defrontar-se com problemas comuns, específicos da esfera supra-estatal.

O objetivo deste artigo é analisar a capacidade da sociedade internacional, das instituições internacionais e do direito internacional de enxergar os problemas comuns da Revista Juris Poiesis - Rio de Janeiro. Vol.21-n ${ }^{\circ} 25,2018$, pg.01- 20. ISSN 2448-0517 
humanidade para além dos interesses nacionais, em tempos de fragmentação, nacionalismos e populismos.

A metodologia utilizada é a fenomenológica, constatando os fatos para, a partir dos mesmos, tecer possibilidades explicativas com potencial de fornecer um quadro compreensivo da realidade que se tenta abranger.

É impossível hoje entender os problemas mais prementes - e as oportunidades que podem advir do seu equacionamento - por meio de um único quadro local ou mesmo nacional. Os avanços rápidos na alta tecnologia continuarão a ter consequências profundasque desafiarão as fronteiras, moldando o ambiente político,jurídico, intelectual, sócio-econômico e militar de maneira que dificilmente pode-se imaginar um mundo menos interligado.

Dadas essas constatações, na primeira seção desenvolve-seuma sucinta análise da sociedade internacional, seus problemas comuns e sua dificuldade de representatividade de participação em um mundo globalizado e interdependente. Da mesma forma se critica o atual discurso nacional populista que prega a fragmentação e a exclusão.

Na segunda seção explorar-se-áa dificuldade das instituições internacionais em fixar regimes jurídicos de forma a atender os anseios comuns da sociedade internacional.

Na ultima seção se examinará a necessidade do Estado de se readaptar aos novos atores que compõem o sistema internacional, no sentido de torna-lo uma organização politica apta a responder em conjunto com os outros atores aos anseios de uma sociedade internacional que possui mais problemas comuns do que interesses nacionais.

\section{2- A sociedade internacional e seus problemas comuns}

Existem muitos estudos que reivindicam das sociedadeso enfrentamento da crise de seus modelos democráticos, principalmente discussões relativas à representatividade de participação e de legitimidade dos atores políticos envolvidos no âmbito global. (MAGALHÃES, 2012; BAUMAN \& BORDONI, 2016; GURRUTZAGA \& GUELL, 2007; ROSENAU \& CZEMPIEL, 2000) As discussões sobre governança, ainda que tragam uma carga grande de discursos ideológicos, abrem as discussões sobre o espaço público nos âmbitos local e mundial. Constituem-se aí novas formas de subordinações e solidariedades cidadãs ante a necessidade de integra-las na difícil equação da democracia em nível mundial. ${ }^{3}$

\footnotetext{
${ }^{3}$ Os estudos sobre democracia no ambito mundial apontam uma diminuicão. Relatório da revista britânica The Economistdivulgado recentemente aponta um declínio nos governos democráticos pelo Mundo, não só na forma Revista Juris Poiesis - Rio de Janeiro. Vol.21-n²5, 2018, pg.01- 20. ISSN 2448-0517 
Com efeito, no processo de globalização, a humanidade passou a compartilhar fronteiras muito mais flexíveis,com a consequente quebra de isolamento dos Estados,ainda que discursos isolacionistas voltem sempre a surgir. Manuel Castells já apontava que os Estados cada vez mais são incapazes de tratar os problemas globais isoladamente. A sociedade civil tem contribuído para a solução desses problemas. Nas palavras de Castells...o humanismo global estaria lentamente minando os últimos princípios lógicos que justificam a necessidade da existência do Estado Nação". (CASTELLS, 1999, p. 313)

Ora, o Estado nação não deixou de existir. Ele ainda representa uma forma de organização política importante e que tem os seus aspectos essenciais frente à organização da vida em sociedade. No entanto, com a constituição de outros importantes atores no âmbito do sistema internacional, deixou de ser o único ator relevante.

Atualmente alguns discursos exacerbados revelam nacionalismos populistas e isolacionismos em nome do bem da sociedade local. Evidencia um certo tipo de cegueira imaginarque a sociedade local de hoje deixará de se envolver com o que acontece do outro lado do globo. A tecnologia nos leva necessariamente para a ampliação dos espaços de convivência e cooperação em termos mundiais, independentemente de barreiras levantadas em relação ao outro.

O fortalecimento da sociedade civil transnacional é mais um fator que indica que o poder estatal não satisfaz sozinho, os anseios da humanidade. Surge assim a necessidade de operar com novas categorias, sendo uma das principais a de sociedade transnacional.

A sociedade transnacional é definida aqui como o conjunto social resultante das interações diretas entre os atores pertencentes a sociedades de diferentes Estados. Seus atores são os indivíduos ou entidades cujas ações transcendam as fronteiras de seus Estados. (CASTEDO, 1989, p. 29)

O elemento transnacional está cada vez mais acentuado em termos de movimento de bens, informações e ideias através das fronteiras nacionais, sem uma participação direta e significativa de atores governamentais. Engloba tanto atores públicos quanto privados com ênfase na atividade dos últimos. (FALK, 1975)

A sociedade internacional concebe os Estados como organizações humanas -sendo a mesma antes de tudo uma sociedade de Estados, conforme Martin Wight já apresentava.

do regime, mas também na aplicação das leis, obrigações e liberdades individuais. A conclusão do estudo, que usa cinco categorias principais de avaliação, é que menos de $5 \%$ da população mundial vive em uma democracia. https://www.economist.com/blogs/graphicdetail/2018/01/daily-chart-21 
Segundo o autor, muitos críticos afirmam a não existência de uma sociedade internacional, pois não haveria os requisitos do que normalmente chamamos de sociedade ${ }^{4}$ (WIGHT, 2002).

A Globalização levou os Estados avançados a cooperar entre si pelo benefício mútuo. As democracias industrializadas obtiveram avanços consideráveis relacionados ao bem-estar, independentemente do nítido efeito excludente. O Estado moderno é, em geral, apresentado pela teoria como fundamental por fornecer ou buscar fornecer segurança, liberdade, ordem, justiça e bem-estar para a população. ${ }^{5}$ (MATIAS, 2014)

De seu lado, Habermas afirma que a Globalização não constitui um processo de desenvolvimento que atingiu seu estágio de estabilização. Essa intensificação das relações de troca, de comunicação e de trânsito e as demais interações sociais para além das fronteiras nacionais, também expressadas como a expansão massificada das telecomunicações, turismo, cultura, com reflexos no ecossistema e nas relações das organizações governamentais e não governamentais, correspondem ao conceito de globalização como um processo e não como algo acabado (HABERMAS, 2001).

O problema é que o Estado moderno não dá mais conta dos problemas comuns da humanidade no âmbito global. Meio ambiente, direitos humanos, desarmamento, mudanças climáticas são apenas alguns exemplos de problemas que estão além do Estado, alguns colocando inclusive o próprio risco de extinção da humanidade em não havendo soluções no âmbito da sociedade internacional.

André Arnaud já apontava que a Globalização surgiu a partir da tomada de consciência do fato de que a sociedade contemporânea tornou-se uma sociedade do risco, onde ocorre a existência de interesses comuns pelo globo e a necessária gestão por outros caminhos que não as regulações tradicionais. A globalização desafia a concepção de ordem mundial enquanto equilíbrio entre estados-nações soberanos com base no direito internacional. Deixa de haver uma linha de demarcação nítida, havendo imbricações, interrelações e interpretações que se confundem ao ponto de paralisar a aplicação das regras de uma ou outra ordem jurídica. (ARNAUD, 2005, p.2)

\footnotetext{
4Segundo Wight, a sociedade internacional apresenta algumas peculiaridades, pois é composta por outras sociedades mais organizadas - os Estados; o número de seus membros é relativamente pequeno, em torno de 200; seus membros são mais heterogêneos do que os indivíduos; seu tempo de vida ultrapassa em muito a duração da vida humana. A comprovação da existência da sociedade internacional é a existência do direito internacional (WIGHT, 2002, p. 98-99).

${ }^{5}$ É importante termos em mente que os Estados são instituições históricas, isto é, estão suscetíveis a mudanças. A cooperação supranacional, por exemplo, começou a surgir em outros contextos a partir da configuração das primeiras organizações internacionais.
} 
Ao longo dos últimos cinquenta anos os problemas comuns da sociedade internacional se intensificaram da mesma forma que a governança global, entendida esta última como conjunto de procedimentos e instituições voltados à solução daqueles problemas. O atendimento aos anseios da humanidade se afastou do contexto restrito dos governos nacionais e passou a ser uma governança de múltiplos níveis. Os participantes não são simplesmente governos e organizações internacionais tradicionais, mas também organizações não governamentais e outros atores não estatais. Uma parte da governança de múltiplos níveis reflete uma cooperação convencional mais intensa entre Estados independentes e parte dela representa uma transformação mais profunda em direção ao que se preconizava: governança supranacional. (GONÇALVES \& COSTA, 2011).

A sociedade civil global, no âmbito da governança, reflete o conjunto de atores transnacionais que tentam monitorar questões que estão fora do controle de cada nação. Esses atores buscam redefinir o papel das agências internacionais e suas relações com as instituições nacionais e organizações da sociedade civil, de forma a adotar regras e princípios democráticos. ${ }^{6}$

De Julios Campuzano já descrevia a crise da relação Estado nação e sociedade a partir dos estudos sobre o constitucionalismo em um contexto de globalização propondo a articulação de dois grandes contratos: um contrato global para a satisfação das necessidades de melhorar a ordem econômica por intermédio de algumas instituições internacionais; e um contrato global para a paz, a tolerância e o diálogo entre as culturas cujo sucesso estaria vinculado aos direitos humanos e na busca de harmonização entre os aspectos do universalismo e da multiculturalidade. (Um contrato global para o desenvolvimento sustentável que harmonizasse o progresso com a natureza e por último um contrato global democrático a partir da necessidade de uma participação política em escala global). (CAMPUZANO, 2009, 105-110)

Gunther Teubner também questiona como a teoria constitucional inserida na tradição nacional-estatal poderia lidar com os novos desafios que se esboçam com três grandes tendências contemporâneas: a esfera digital, a privatização e a gênese das redes globais.

Diante da constatação que não é aplicável às constituições civis globais a dicotomia público/privado, Teubner entende que o Direito Internacional Público e o Direito Privado

6 Segundo Teixeira, observa-se a existência de uma sociedade civil global em processo de constituição, um conjunto heterogêneo de organizações sociais, movimentos, grupos de cidadãos, ONGs que se articulam em redes sociais e eletrônicas, criando espaços públicos autônomos ou utilizando-se de esferas públicas institucionais para o debate crítico e propositivo de questões gerais que afetam a sociedade (TEIXEIRA, 2002). 
transnacional deveriam cooperar na analise constitucional dos regimes globais. A teoria dos sistemas ofereceria três critérios: a) a sociedade mundial somente pode ser constitucionalizada de forma fragmentaria, em constituições de âmbitos sociais setoriais; b) um sistema jurídico global não unitário, mas fragmentado; e c) não se deveria contar com uma integração das constituições civis parciais por uma constituição política de conjunto, mas se pode afirmar que na colisão de diversas constituições parciais se originam conexões em rede das constituições. (TEUBNER, 2005)

Já a partir de uma ótica construtivista, Nicholas Onuf salienta que tanto as regras quanto a realidade social são relevantes para o universo jurídico. Em sua concepção de Constituição da Sociedade Internacional Onuf parte da constatação de que qualquer sociedade apresenta características diferenciadas; assim a sociedade internacional é entendida tanto como objeto como também um processo. $\mathrm{O}$ autor, ainda que indique que a sociedade internacional não tem uma constituição que seja anunciada como tal, argumenta que existem rudimentos de uma Constituição em sentido material no que denomina como o mais importante tratado multilateral acordado entre Estados até hoje na história da humanidade - a Carta da Nações Unidas. (ONUF, 1994, p. 1-19)

Portanto, observa-se que, para além de importantes argumentos que sustentam a existência de problemas comuns frente à sociedade internacional, a sua representatividade ainda é muito frágil, pois encontramos um déficit democrático muito grande no âmbito das instituições internacionais e das próprias ordens jurídicas internacionais se comparado ao existente no âmbito do Estado nação.

Com efeito, a questão da legitimidade democrática, embora sujeita ao relativismo conceitual, é atributo inerente à vida política em determinada sociedade, e, portanto,no âmbito estatal se traduz em requisito constitucional essencial. Esse problema também é anotado por Dunoff e Trachrman ao mencionarem a crítica que muitos fazem a propósito do déficit democrático encontrado em várias ordens jurídicas internacionais, justamente diante da possibilidade que as normas jurídicas internacionais possam ser mais isoladas das práticas de legitimação democrática que se verificam no plano doméstico.

Por outro lado, também cabe enfatizar que a democracia é desigual no âmbito do sistema de Estados. Não parece fácil tratar de um sistema constitucional global que se pretenda democrático se muitas das unidades políticas estatais ainda caminham a passos lentos nesse campo. (DUNOFF; TRACHTMANN, 2009) 
A fragmentação setorial das normas globais e das instâncias decisórias também aparece como um importante fenômeno a se considerar tendo em vista o direito internacional. Atualmente a proliferação de regimes normativos especializados no campo internacional como os direitos humanos, a proteção ambiental, o comércio e desarmamento, além dos tribunais internacionais, configuram um cenário fragmentado. (VIVIANI, 2014, P.250)

José Filipe Pinto salienta que o globalismo, tal como a crise do início do século XXI, não tornou despiciente a ideia de nação nem de região. Muitos dos partidos assumidamente regionalistas ou nacionalistas, ao nível do discurso, não se afastam dos partidos populistas, uma vez que na defesa dos particularismos da identidade regional e/ou nacional acabam, com frequência, por assumir uma atitude, ainda que nem sempre explícita, de recusa do outro.(PINTO, 2017)

As características da governança explorada de uma forma crítica indicam que a mesma envolve, no afazer político, as autoridades estatais e locais, bem como o setor de negócios, o sindicato de trabalhadores e os agentes da sociedade civil, tais como ONGs e os movimentos populares. Todos esses investidores participam nesse tipo de negociação. É um processo de tomada de decisão relativamente horizontal, em oposição ao estilo mais hierárquico do governo tradicional. Sem embargo, a participação está bem longe de ser igualitária, uma vez que certos investidores influenciam os resultados muito mais do que outros. ${ }^{7}$ (KAZANCIGIL, 2002 , p. 53 - 54)

Keohane e Nyejá destacavam que a interdependência não pode ser tratada somente pelo viés liberal, pois este apenas pensa em termos de ganho conjunto, ou seja, em situações de resultado positivo nas quais todos se beneficiam e todos melhoram. Seria ingênuo pensar dessa forma e não prestar atenção na desigualdade dos benefícios e nos conflitos que surgem com relação à distribuição dos ganhos relativos, pois deixam-se de considerar os aspectos políticos da interdependência. Os custos da interdependência podem envolver uma sensibilidade a curto prazo ou uma vulnerabilidade a longo prazo (KEOHANE\& NYE, 1989).

$7 \mathrm{O}$ modelo de governança se adapta muito bem às condições da cena multinacional, na qual não há nenhuma autoridade central e na qual os investidores, isto é, os Estados soberanos, as corporações multinacionais, as organizações internacionais e mais recentemente as ONGs, geram políticas sobre questões específicas e regimes regulatórios, através de negociações. A governança, até o momento, teria se baseado nos princípios de efetividade e eficiência. Seria participativa, mas, por envolver apenas esses investidores interessados na questão em consideração, não substitui as instituições democráticas, as quais representam a totalidade dos cidadãos e tratam de interesses multissetoriais comuns da sociedade como um todo (MILANI, ARTURI, SOLINÍS, 2002). 
A partir das considerações acima se verifica que a sociedade internacional atual possui dificuldade para refletir seus problemas comuns. Ainda que o Estado nação não tenha deixado de existir, ele por si só não dá mais conta dos problemas comuns da humanidade. A partir do momento em que o mundo passa a organizar-se segundo um novo paradigma, é natural que outros níveis de poder surjam para alcançar os objetivos e resolver os problemas decorrentes dessa mudança. Uma sociedade global exige instituições globais e estas não podem ser diminuídas por discursos nacionalistas populistas que desconsideram justamente o processo evolutivo dessas instituições para o bem da humanidade. Pelo contrário, deve-se passar a explorar o papel das instituições internacionais e o direito cosmopolita no sentido de dar voz às reivindicações da sociedade internacional para solucionar os problemas comuns.

\section{3- Instituições internacionais e o populismo nacionalista: mais cooperação, menos}

\section{fragmentação}

Se observarmos o atual discurso populista que ressurge vigoroso no seio dos Estados contemporâneos, constataremos inevitavelmente que o mesmo - ao apelar para uma peculiar simbologia nacionalista - estimula a fragmentação e a exclusão do outro, e, portanto,não favorecendo em nada a consolidação das instituições internacionais e o processo de governança global. Esse discurso pressupõe um viés excludente, onde o mundo é visto a partir dos interesses nacionais, sem uma perspectiva do quadro maior que conecta a atual sociedade internacional em seus problemas comuns.

Para empreender uma análise mais aprofundada desse quadro, impõe-se preliminarmente delinear uma definição do que seja essa prática política. Nesse particular, parece adequada a conceituação de Tapia (2013), para quem o populismo é uma estratégia carente de ideologia que se manifesta antes, durante e após os processos eleitorais, com os seguintes elementos constitutivos: um discurso popular onde oferece remédios instantâneos às demandas sociais, ataca seus inimigos (rivais/contendores/instituições) ou cria inimigos fictícios, dirige-se a um segmento policlassista, apesar de enfatizar o seu interesse em pessoas de escassos recursos. Já no poder, recusa mediações institucionais, pois privilegia o contato direto com a população. Neste sentido, debilita as instituições tradicionais, mas pelo contrário cria uma nova institucionalidade que lhe garanta nichos eleitorais. Saliente-se ainda que, diferentemente do populismo clássico, ele usa a mídia privada e pública, pois tenta estabelecer um contato permanente com as pessoas. 
De fato, o populismo considerado como política - ou seja, como prática de governo ${ }^{8}$ - apresenta como características mais conspícuas as seguintes: a) postula a categoria "povo" como uma unidade sociológica contraposta à "elite", utilizando-se da dicotomia amigo/inimigo; b) endossa um acentuado descolamento dos procedimentos democráticos; c) consolida uma diminuição das instâncias representativas, estabelecendo assim uma conexão direta entre o dirigente e a massa; d) promove a mobilização permanente da nação em torno de determinados símbolos; e e) tal mobilização se dá frequentemente pela criação de um inimigo comum; que amiúde é externo (ALTERIO, 2016).Sobre este aspecto particular, assevera Marchettoni, (2017): la politica populista è sempre una política delle identità, che contrappone un concetto artificiale di popolo a un "nemico" ugualmente fantomatico, moralizando la contrapposizione.

De seu lado, Laclau (2013) centrando sua atenção mais no discurso do que na prática, verifica algumas características sui generis daquele, tais como a negação da identificação com direita ou esquerda, por apresentar-se como um movimento multiclassista, a sua reivindicação de participação política universal - o que evidencia uma contradição, pois o populismo é essencialmente autoritário - e o privilegiamento de certos temas como a justiça social, a defesa da pequena propriedade e das pessoas comuns, negação da importância da categoria "classe", e finalmente (o que tem a ver com o tema deste ensaio) componentes fortemente nacionalistas.

De qualquer sorte, a palavra "populismo" é um termo ao qual falta um referente empírico unívoco e que admite diversas concretizações no tempo e no espaço. Portanto, pode ser encontrado em diversos eventos, desde o populismo americano - de Andrew Jackson ao populismo reacionário de Donald Trump (CANOVAN, 1999) - até países europeus como a Inglaterra (Brexit), Alemanha (neonazismo) França (Frente Nacional) e Itália (Berlusconi e movimento 5 Stelle) (MARCHETTONI, 2017).

Estes avatares confirmam o fato de que o populismo configura-se como uma forma de reação a um complexo de fatores - entre os quais a globalização - onde o aumento da desigualdade econômica desempenha um papel preponderante.

Ora, a concretização dos objetivos dos líderes populistas - a partir das características mencionadas acima - exige um ambiente de claro encerramento das práticas políticas no interior dos Estados-nação: o êxito desse tipo de dominação depende fortemente da exclusão e

\footnotetext{
${ }^{8}$ Pois o populismo pode ser encontrado também em ações administrativas, judiciais etc. como por exemplo, em decisões judiciais não pautadas pelas leis e constituição, mas visando ao atendimento do clamor popular.
} 
o enfrentamento do perigo que é representado pela comunidade internacional e suas instituições ${ }^{9}$.Em resumo, trata-se de recusa a uma maior inserção na ordem internacional, uma radical desconfiança em relação ao outro.

Ora, a cooperação é vital ao multilateralismo. Os limites da concepção do estado centrismo na atual conjuntura do mundo contemporâneo e as transformações no formato institucional do multilateralismo provavelmente dificultariam em muito a volta ao mundo protecionista e fragmentado, ainda que discursos de algumas lideranças estejam promovendo essa viragem.

Os Estados soberanos continuam por isso sendo peças essenciais da sociedade global. Eles são ainda os principais responsáveis por assegurar a paz e a segurança dentro e fora de seus territórios, por garantir a justiça e a coercitividade das normas nacionais e internacionais, por buscar alcançar o bem estar de sua população e a justiça social. São ainda a maior garantia de que um poder legítimo será exercido sobre a sociedade.

Por outro lado, a primeira função de um sistema de governança é garantir a segurança de seus membros, fornecendo a regras e os procedimentos que previnem, ou ao menos reduzem, os conflitos internos, assim como os mecanismos capazes de responder às ameaças externas. É importante notar que os Estados mantêm o monopólio do exercício da violência legítima em seus territórios. Esse monopólio é a razão original da existência do Estado e consiste em uma espécie de núcleo duro de suas atribuições. (BIANCHI, 2014)

As instituições internacionais ganharam muita importância ao longo dos últimos anos, mas também há críticas constantes ante o problema do déficit democrático e de representatividade. Muitas dessas instituições atuam de forma muito distante do cidadão comum. Apesar disso, elas possuem hoje uma importância muito grande diante do conjunto de demandas do sistema internacional. Os Estados veem-se impotentes para dar conta de muitas dessas demandas.

As instituições multilaterais facilitam a cooperação internacional e influenciam o comportamento dos Estados a partir da constituição da agenda, o monitoramento da compliance (conformidade às regras) e outras funções. Mesmo em condições de anarquia os

\footnotetext{
${ }^{9}$ Como é óbvio, o populismo não ignora a existência dessa realidade mundial; apenas a aborda como fenômeno externo não passível de incorporação. Villacañas Berlanga (2015) pondera que fenômenos como o populismo, que não são em essência internacionalistas, observam os processos internacionais de maneira muito rica e complexa. Por exemplo, adota a corrente do subalternismo, surgida das "cinzas da teoria marxista", para aplicar à América Latina como sociedade pós-colonial. (BERLANGA, 2015)
} 
Estados irão frequentemente se engajar em comportamentos de cooperação facilitado pelas instituições internacionais que reduzem as inseguranças.

A proliferação de organizações internacionais durante o último século marcou a transformação da velha ordem internacional numa nova ordem mundial, centrada no sistema das Nações Unidas; contudo, as fontes fundamentais da ordem internacional - a guerra, a balança de poder, o papel das grandes potencias, o Direito Internacional e a diplomacia tradicional - continuaram a funcionar. Se por um lado entramos em uma nova ordem, assente sobretudo no papel das Nações Unidas, por outro vigoram ainda as principais premissas do realismo, mesmo em termos de ONU. Embora estejam bem presentes princípios que tendem a valorizar a paz e a segurança, a agenda tradicional, a agenda das Nações Unidas, abrange muitas outras áreas de preocupação, como economia, cultura, finanças ou social. (MULDOON, 2007)

Uma das maiores contribuições para o aumento da importância da diplomacia multilateral e do próprio multilateralismo é o processo de globalização presente em especial no pós-guerra fria. O mundo ficou menor: os transportes e as telecomunicações, em especial, vieram a imprimir uma dinâmica mais global às relações, não apenas estatais, mas também organizacionais e pessoais: indivíduos e bens começaram a mover-se de nação para nação com uma facilidade e velocidade considerável. (ALVEZ, 2014)

A globalização e a crise da soberania intensificaram as críticas sobre a natureza do direito internacional, como a lei do Estado do ponto de vista sociológico, funcional e ético. Essas críticas têm frequentemente procurado projetar um valor material ou uma ideia de justiça social fora do Estado, imposta pelo direito internacional.

Nesse passo, o reconhecimento da relevância dos princípios da prudência não significa ignorar o conjunto de instituições e regras que indicam o comportamento prudencial e, tampouco, reduzi-las à dinâmica do exercício do poder no cenário internacional (a centralidade das instituições internacionais e regras que informam a dinâmica da sociedade de Estados e os seus limites no que concernem à previsão de ordem internacional). ${ }^{10}$ (ESTEVES, 2003)

\footnotetext{
${ }^{10}$ Keohane, Nye e Krasner nos anos 80 produziram todo um debate sobre as organizações internacionais e a relação dessas ante os regimes internacionais como fenômeno mais amplo da cooperação na anarquia. Se procurava explicar porque os Estado soberanos que definiam os seus interesses de forma racional e egoísta, cooperam na criação de regimes que são os princípios, normas, regras e procedimentos que prescrevem comportamentos e geram expectativas futuras.
}

(KRASNER, 1982) 
Já a partir de seu locus, o institucionalismo se propôs a corrigir a grave deficiência do realismo estrutural, observando as instituições como variáveis intervenientes, capazes de explicar como atores com preferências diferentes resolvem seus conflitos por meio da construção de arranjos cooperativos que podem, inclusive, mudar a ordem de tais preferências de modo a superar impasses frequentemente encontrados em um sistema anárquico. ${ }^{11}$ (NOGUEIRA, 2003, p.26)

$\mathrm{O}$ fato é que vivemos em uma sociedade internacional. Isso significa que queremos de alguma maneira e que somos moldados pelas normas sociais, regras, entendimentos nos relacionamentos que temos com os outros.

Temos uma infinidade de problemas comuns em termos de desafios para o futuro da humanidade. É por meio das instituições internacionais que esses problemas comuns podem, pelo menos, ser melhor discutidos.

Como visto acima, a volta a um nacionalismo populista que incentiva a fragmentação e ao isolacionismo a partir do desestímulo das instituições internacionais e ao multilateralismo é um retrocesso. É a partir disso que abordamos a seguir a sociedade internacional e o problema dos interesses nacionais a partir de uma perspectiva para além dos Estados.

\section{4 - Mais problemas comuns do que interesses nacionais: a sociedade}

\section{internacional vai além dos Estados}

Dificilmente pode ser negada a existência de um sistema de Estados. Admitir que tal sistema existe é admitir, em parte, a existência de uma sociedade, pois uma sociedade corresponde a um certo número de indivíduos ligados por um sistema de relacionamentos com objetivos e problemas comuns. Esses objetivos e problemas comuns estão hoje ainda mais interligados no âmbito da sociedade global ainda que discursos extremistas apareçam no sentido de negar os aspectos comuns dos anseios da humanidade.

Não há um governo mundial acima dos Estados soberanos. ${ }^{12}$ No entanto, há interesses, regras, instituições e organizações comuns criados pelos Estados para ajudar a

\footnotetext{
${ }^{11}$ A opinião dos neoliberais coincidia com as posições de correntes homônimas das Ciências Sociais ao afirmarem que a internacionalização de processos econômicos e políticos, característica de um mundo cada vez mais interdependente ou globalizado, requer a construção de instituições que transferissem parcela significativa das decisões para o âmbito supranacional, ao mesmo tempo em que restringiam a capacidade e a liberdade de ação autônoma (ou unilateral) dos policy-makers no interior dos Estados.

12É importante salientar que a escola inglesa está de acordo com os realistas clássicos nos estudos sobre Relações Internacionais. Reconhecem a relevância do poder nas questões internacionais e enfatizam o Estado e o 
constituir a interação entre eles. Hedley Bull cunhou a expressão sociedade anárquica: há uma ordem social mundial composta por Estados independentes (BULL, 2002).

Nos dias atuais, se formos olhar para esses Estados, constataremos que eles são ainda mais interdependentes do que eram no passado. Os ganhos por meio da cooperação internacional são muito mais positivos e beneficiam diretamente toda a sociedade internacional. ${ }^{13}$ Isso não significa dizer que se deseja uma sociedade internacional homogeneizada, as diferenças são parte da humanidade.

Segundo Martha Finnemore, a vida social internacional ao final do século XX é organizada em torno de três elementos normativos fundamentais: burocracias, mercados e igualdade humana. Ao longo dos últimos séculos, o consenso sobre a bondade e a adequação desses princípios organizadores da vida política e social cresceu e transformou a política internacional. (FINNEMORE, 1996, p. 130)

As tensões e a contradição entre os princípios normativos na vida internacional significam que não existe um conjunto de arranjos políticos e econômicos de idílios para os quais todos estamos convergindo. Não existe um equívoco estável, nenhum fim da história. Em vez disso, as instituições sociais continuamente estão sendo contestadas, embora em graus variados em momentos diferentes. As declarações normativas não resolvidas em um conjunto de compromissos sociais podem ser a força mobilizadora para ataques a esse complexo de arranjos, pois as pessoas articulam reivindicações normativas constantes.

Esses processos de contestação, principalmente no âmbito dos Estados, são políticos. De fato, a contestação normativa é, em grande parte, a política sobre aquilo de que se trata: valores competitivos e compreensão do que é bom, desejável e qual o apropriado grau de invasão do governo na vida dos cidadãos são todos temas de debates precisamente porque não existe uma solução normativa estável e clara. (FINNEMORE, 1996, p. 131)

A política internacional não está destituída de normas legais apesar da inexistência de um órgão central responsável pela elaboração e implementação das normas. A politica internacional é governada por princípios e regras que possuem validade através do reconhecimento geral dos atores e dos procedimentos que lhes dão origem.

sistema estatal. Rejeitam a visão realista limitada de que a política mundial é um estado de natura hobbesiano desprovido de normas internacionais.

13A Sociedade internacional é entendida nesse trabalho como uma sociedade que convive atualmente com a existência de normas e instituições comuns que são suficientes no sentido de ter preocupações e reivindicações comuns de âmbito global. (BULL 2002) 
Até a própria anarquia está baseada em princípios normativos,como a de igualdade de soberania entre os Estados - parte do direito internacional. Esse princípio, junto com outros como o pacta sunt servanda, formam o núcleo da comunidade dos Estados. Nas instituições internacionais o processo de constituição de políticas é canalizado através da estrutura institucional de seu sistema político. Os impulsos e conteúdos dessa política são derivados dos interesses e recursos dos atores envolvidos. A política instituída a partir das instituições internacionais fornece um arcabouço normativo institucional ao sistema internacional no qual amplia ou limita as opções dos atores na política internacional e consequentemente define possíveis direcionamentos ao passo em que exclui outros. (RITTBERGER, 2012)

O Estado necessita se readaptar aos novos atores que compõem o sistema internacional no sentido de torná-lo uma organização política apta a responder em conjunto com esses outros atores aos anseios de uma sociedade internacional que possui mais problemas comuns do que interesses nacionais.

É por isso necessário pensar o novo: as velhas estruturas mentais adequadas aos Estados-nações, conquanto necessárias para resolver problemas pontuais, já tem se revelado de todo insuficientes para dar conta dos problemas emergentes.

O grau de aproximação que o planeta vem proporcionando com o aumento da tecnologia, a circulação em massa de indivíduos exige um conjunto normativo que de conta dos problemas comuns existentes na humanidade, esses problemas vão além do Estado. Meio ambiente, direitos humanos, desarmamento são apenas alguns dos temas que levam a necessidade de se buscar soluções comuns.

Segundo Andrew HURRELL cada vez mais considera-se que a ordem envolve a criação de normas internacionais que afetam profundamente as estruturas e a organização domésticas dos estados, investem indivíduos e grupos de estados de direitos e deveres, além de buscarem incorporar alguma noção de bem comum global.

Para esse autor há dois conjuntos de fatores que explicam essa mudança. O primeiro é material e o segundo, moral. Em primeiro, o objetivo de uma ordem mínima tornou-se cada vez mais inadequado, dado a alcance e a gravidade dos problemas e desafios apresentados à sociedade internacional. Particularmente, a ampliação da interdependência e o grau no qual sociedades individuais dependem umas das outras para obter segurança, prosperidade e capacidade para controlar seu ambiente denotam que a legitimidade dos Estados depende atualmente da sua capacidade de satisfazer um vasto e incrementado leque de necessidades, demandas e exigências. Em segundo o moral, pois resulta da emergência de uma consciência 
moral cosmopolita, ainda que frágil, mas que demanda maior atenção a questões de direitos humanos individuais e coletivos, como também à promoção de padrões mínimos de bem-estar e prosperidade humanos mundo afora. (HURRELL, 1999)

Hurrew ainda explica que a bem-sucedida consolidação de uma sociedade internacional que se adensa em certas partes do mundo, leva a divisões entre os integrados e os que estão fora. $\mathrm{O}$ autor questiona em havendo uma sociedade internacional, quais seriam os seus limites? Esta incorporaria toda a raça humana ou se limita a um espaço em particular? Uma vez sendo limitada, quais são seus princípios de inclusão e exclusão? Por um lado, há uma longa tradição de doutrinas e de ideias ocidentais orientadas por princípios de exclusividade, baseadas em ser cristão, ser europeu, ou ser "civilizado"; por outro lado, há uma forte contracorrente no pensamento ocidental que manteve a existência de uma comunidade universal da humanidade, que retira sua inspiração básica na antiga tradição da lei natural. (HURRELL, 1999)

Essas questões levantadas por Hurrell são muito importantes e retratam a preocupação de uma sociedade internacional que vai além do Estado. Compreender o conjunto de regras formais ou informais, jurídicas ou morais - que condicionam o comportamento dos indivíduos e as instituições que fornecem a estrutura no qual os seres humanos interagem, pois são responsáveis por delinear as relações de diversos atores de uma sociedade é de grande valia para se compreender os problemas comuns que estão acima dos interesses nacionais.

\section{5 - Conclusão}

É muito difícil nos tempos atuais compreender os problemas da humanidade - e as oportunidades que surgem do seu equacionamento por meio de uma exclusiva visão local e nacional. Com o avanço rápido da alta tecnologia alterações profundas desafiam as fronteiras, promovendo mudanças no ambiente político, jurídico, intelectual, sócio-econômico e militar o que é difícil de imaginarmos um mundo menos interligado.

Ao analisarmos a capacidade da sociedade internacional, das instituições internacionais e do direito internacional de enxergar os problemas comuns da humanidade para além dos interesses nacionais, em tempos de fragmentação, nacionalismos e populismos observamos que não é algo simples, uma vez que muitas variáveis ainda levam a uma visão de mundo instituída sob a imagem do Estado nação. 
Se observam discursos exaltados nos tempos atuais revelando nacionalismos populistas e isolacionismos em nome do bem da sociedade local. Esses discursos promovem um tipo de cegueira a partir de uma visão deque a sociedade local de hoje deixará de se envolver com o que acontece no mundo. A ampliação dos espaços de convivência e cooperação em termos mundiais se tornou algo quase que inevitável com o aumento da tecnologia, independentemente de barreiras levantadas em relação ao outro.

O fortalecimento da sociedade civil transnacional é mais um fator que indica que o poder estatal não satisfaz sozinho os anseios da humanidade. Surge assim a necessidade de operar com novas categorias, sendo uma das principais a de sociedade transnacional.

A proliferação de líderes populistas a partir das características mencionadas ao longo do texto - exige um ambiente de claro encerramento das práticas políticas no interior dos Estados-nação: o êxito desse tipo de dominação depende fortemente da exclusão e o enfrentamento do perigo que é representado pela comunidade internacional e suas instituições.

Os Estados soberanos continuam por isso sendo peças essenciais da sociedade global. Eles são ainda os principais responsáveis por assegurar a paz e a segurança dentro e fora de seus territórios, por garantir a justiça e a coercitividade das normas nacionais e internacionais, por buscar alcançar o bem estar de sua população e a justiça social. São ainda a maior garantia de que um poder legítimo será exercido sobre a sociedade.

Sendo assim, conclui-se que, para além de importantes argumentos que sustentam a existência de problemas comuns frente à sociedade internacional, a sua representatividade ainda é muito frágil, pois encontramos um déficit democrático muito grande no âmbito das instituições internacionais e das próprias ordens jurídicas internacionais se comparado ao existente no âmbito do Estado nação.

O Estado necessita se readaptar aos novos atores que compõem o sistema internacional no sentido de torná-lo uma organização política apta a responder em conjunto com esses outros atores aos anseios de uma sociedade internacional que possui mais problemas comuns do que interesses nacionais. Cabe a humanidade decidir sobre até onde poderá excluir essas preocupações para a sua própria sobrevivência.

\section{Referências}


ALTERIO, A.M. El constitucionalismo popular y el populismo constitucional como categorías constitucionales, in GARGARELLA, R.; ORTEGA, R. Constitucionalismo progressista: retos y perspectivas. México, UNAM, 2016.

ALVEZ, F. A Diplomacia Multilateral da ONU em PINTO, Maria do Céu. (ORG) As Nações Unidas e os Desafios da Governança Global. Lisboa, Letras Intinerantes, 2014.

ARNAUD, André-Jean. (Org.). Globalização e Direito I: impactos nacionais, regionais e transnacionais. 2. Ed. Rio de Janeiro: Editora Lumen Juris, 2005.

BAUMAN, Z.;BORDONI, C. Estado em Crisis. Barcelona. Ed. Paidos, 2016

BIANCHI, Alvaro. O conceito de estado em Max Weber. Lua Nova, São Paulo , n. 92, p. 79-104, Aug. 2014 Disponível em: $<$ http://www.scielo.br/scielo.php?script=sci_arttext\&pid=S0102-

$64452014000200004 \& \operatorname{lng}=\mathrm{en} \& \mathrm{nrm}=\mathrm{iso}>$. Acesso

em 02 Marco. 2018. http://dx.doi.org/10.1590/S0102-64452014000200004.

BULL H. A Sociedade Anárquica. Brasilia: Ed. Universidade de Brasilia, IPRI, 2002.

CAMPUZANO, A. Constitucionalismo em Tempos de Globalizacão. Porto Alegre, Livraria do Advogado, 2009.

CANOVAN, M. Trust the People! Populism and the Two Faces of Democracy. PoliticalStudies, 47 (1), 1999.

CASTEDO, A. Derecho de la Integracion Economica Regional. Buenos Aires. Depalma, 1989, p. 13.

CASTELLS, M. O Poder da Identidade: Paz e Terra, 1999

DUNOFF, J; TRACHTMAN, J. A Functional Approach to Global Constitucionalism. Em DUNOFF, Jeffrey; TRACHTMAN, J. (edit) Ruling the World: Constituionalism, International Law and Global Governance. New York:CambridgeUniversity Press, 2009.

ESTEVES, P. Governança Global: ordem e justiça na sociedade internacional, em ESTEVES (Org) Instituições Internacionais: segurança, comércio e integração. Belo Horizonte: PUC Minas, 2003.

FALK, R. A Study of Future World Society. New York: The Free Press, 1975, p. 74.

FINNEMORE, Martha. National Interests in International Society.Ihaca, Cornell University Press. 1996

GONÇALVES, A.; COSTA, J. A. Governança Global e regimes internacionais. São Paulo. Almedina, 2011

GURRUTXAGA, I.; GUELL, P. Democracia Participativa y Desarrollo Humano. Madrid, Dykinson, 2007 
HABERMAS, J. A Constelação Pós-nacional: ensaios políticos. São Paulo: LitteraMundi, 2001

HURRELL, A. Sociedade internacional e governança global. Lua Nova, São Paulo, n. 46, p. 55-75, 1999 Available from <http://www.scielo.br/scielo.php?script=sci_arttext\&pid=S0102$64451999000100003 \& \operatorname{lng}=$ en\&nrm=iso $>$. access on 27 Mar. 2018. http://dx.doi.org/10.1590/S0102-64451999000100003.

KAZANCIGIL, A. A regulação social e a governança democrática da mundialização, MILANI, C.; ARTURI, C.; SOLINÍS, G. Democracia e Governança Mundial, Porto Alegre : Ed. UFRGS, 2002.

KEOHANE, R.; NYE, J. Power and Interdependence. New York : Harper Collins Publishers, 1989.

KRASNER, S. Structural causes and regime consequences: regimes as intervening variables. InternationalOrganization, n. 362, p. 1-21, 1982.

LACLAU, E. A razão populista.São Paulo, Três Estrelas, 2013.

MAGALHÃES, José. Estado Plurinacional e Direito Internacional. Curitiba, Ed. Juruá. 2012.

MARCHETTONI, L. "Teorie del populismo", Jura Gentium, ISSN 1826-8269, XIV, 2017, 2, pp. $1-10$

MATIAS, Eduardo. A Humanidade e suas Fronteiras: do estado soberano à sociedade global. São Paulo: Paz e Terra. 2014

MILANI, C.; ARTURI, C. SOLINIS, G. Democracia e Governança Mundial: que regulações para o século XXI? Porto Alegre : Ed. UFRGS, 2002.

MULDOON, Jr. JAMES P. The New New Diplomacy: The Changing Character of Multilateral Diplomacy at the United States, British International Studies Association, University of Cambridge, UK, 2007. Disponível em: www.bisa.ac.uk/2007/pps/muldoon.pdf Acesso em 30 de outubro

NOGUEIRA, J. Instituições e Governança Global na Teoria da Relações Internacionais: um breve panorama da evolução dos debates nas teorias convencionais. Em ESTEVES, P. L., Instituições Internacionais: segurança, comercio e integração. Belo Horizonte, Ed. Puc Minas, 2003.

ONUF, N. The Constitution of International Society. European Journal of International Law, v.5, 1994, p. 1-19.

PINTO, J.F. Populismo e Democracia: dinâmicas populistas na União Européia. Lisboa. EdicõesSílabo, 2017. 
RITTBERGER, V.; ZANGL, B.; Krock, A. International Organization. Londres:Palgrave. 2012

ROSENAU, j. CZEMPIEL. E. Governança sem Governo: ordem e transformação na política mundial. Brasilia. Ed. UNB, 2000

TAPIA, C.U. El populismo em la democracia. Forum. $\quad \mathrm{N}^{\circ} 4$, Medellín, Colombia, juliodiciembre de 2013

TEIXEIRA, E. C. $O$ Local e o Global: limites e desafios da participação cidadã. São Paulo: Cortez, 2002.

TEUBner, G. El Derecho como Sistema Autopoiético de La Sociedad Global. Lima, ARA Editores. 2005, p.78

VILLACAÑAS BERLANGA, J.L. El populismo. Madrid, La Huerta Grande, 2015.

VIVIANI, M. Constitucionalismo Global: crítica em faze da realidade das relações internacionais no cenário de uma nova ordem mundial. Rio de Janeiro, Lumen Juris. 2014.

WIGHT, M. A Política do Poder. Brasilia, Ed. Unb. 2002 